\title{
Projecting Future Scheduled Airline Demand, Schedules and NGATS Benefits Using TSAM
}

\author{
Samuel Dollyhigh $^{*}$ and Jeremy Smith. ${ }^{\dagger}$ \\ Swales Aerospace, Hampton, VA, 23681 \\ Jeff Viken ${ }^{\ddagger}$ \\ NASA Langley Research Center, Hampton, VA, 23681 \\ Antonio Trani ${ }^{\S}$, Hojong Baik ${ }^{* *}$, Nickolas Hinze ${ }^{\dagger \dagger}$, Senanu Ashiabor ${ }^{\ddagger \ddagger}$ \\ Virginia Polytechnic Institute and State University, Blacksburg, VA, 24061
}

The Transportation Systems Analysis Model (TSAM) developed by Virginia Tech's Air Transportation Systems Lab and NASA Langley can provide detailed analysis of the effects on the demand for air travel of a full range of NASA and FAA aviation projects. TSAM has been used to project the passenger demand for very light jet (VLJ) air taxi service, scheduled airline demand growth and future schedules, Next Generation Air Transportation System (NGATS) benefits, and future passenger revenues for the Airport and Airway Trust Fund. TSAM can project the resulting demand when new vehicles and/or technology is inserted into the long distance (100 or more miles oneway) transportation system, as well as, changes in demand as a result of fare yield increases or decreases, airport transit times, scheduled flight times, ticket taxes, reductions or increases in flight delays, and so on. TSAM models all long distance travel in the contiguous U.S. and determines the mode choice of the traveler based on detailed trip costs, travel time, schedule frequency, purpose of the trip (business or non-business), and household income level of the traveler. Demand is modeled at the county level, with an airport choice module providing up to three airports as part of the mode choice. Future enplanements at airports can be projected for different scenarios. A Fratar algorithm and a schedule generator are applied to generate future flight schedules. This paper presents the application of TSAM to modeling future scheduled air passenger demand and resulting airline schedules, the impact of NGATS goals and objectives on passenger demand, along with projections for passenger fee receipts for several scenarios for the FAA Airport and Airway Trust Fund.

\section{Introduction}

The Transportation Systems Analysis Model (TSAM) developed by Virginia Tech's Air Transportation Systems Lab and NASA Langley can provide detailed analysis of the effects of a full range of NASA and FAA aviation projects on the demand for air travel. TSAM has been used to project the passenger demand for very light jet (VLJ) air taxi service ${ }^{1}$, scheduled airline demand growth and future schedules ${ }^{2}$, Next Generation Air Transportation System (NGATS) benefits, and future passenger revenues for the Airport and Airway Trust Fund. TSAM can project the resulting demand when new vehicles and/or technology is inserted into the long distance (100 or more miles one-way) transportation system, as well as, changes in demand as a result of fare yield increases or decreases,

\footnotetext{
${ }^{*}$ Senior Research Engineer, Swales Aerospace, NASA Langley Research Center, Hampton, VA, 23681, Associate AIAA Fellow

† Senior Engineer, Swales Aerospace, NASA Langley Research Center, Hampton, VA,

‡ Senior Research Engineer, Systems Analysis Branch, NASA Langley Research Center, Hampton, Virginia, 23681.

$\S$ Associate Professor, Department of Civil and Environmental Engineering, Patton Hall 200, Virginia Tech, Virginia, 24061, AIAA Senior Member.

** Research Assistant Professor, Department of Civil and Environmental Engineering, Patton Hall 200, Virginia Tech, Virginia, 24061.

${ }^{\dagger+}$ Research Associate, Department of Civil and Environmental Engineering, Patton Hall 200, Virginia Tech, Virginia, 24061

\# Graduate Research Assistant, Department of Civil and Environmental Engineering, Patton Hall 200, Virginia Tech, Virginia, 24061.
} 
airport transit times, scheduled flight times, ticket taxes, reductions or increases in flight delays, and so on. This paper presents the application of TSAM to modeling future scheduled air passenger demand and resulting airline schedules, the impact of NGATS goals and objectives on passenger demand, along with projections for passenger fee receipts for several scenarios for the FAA Airport and Airway Trust Fund .

TSAM models all long distance travel in the contiguous U.S. and determines the mode choice of the traveler based on detailed trip costs, travel time, schedule frequency, purpose of the trip (business or non-business), and household income level of the traveler. For this particular set of analyses, automobile and scheduled airline were the two travel modes available. Long distance travel is modeled at the county level for the 3091 counties in the U.S. The number of long distance trips generated within each county is based on demographic data for each county and trip rate data from the 1995 American Travel Survey ${ }^{3}$. Demographic projections ${ }^{4}$ are available for each county to the year 2030, thus providing a detailed basis for travel projections for next 25 years. A gravity model with attractiveness factors is used to generate annual numbers of county-to-county trips. To assure accurate representative distances, trips are assumed to be between each county's centroid of population. Automobile trip distances and times are determined from MapPoint (registered trademark, Microsoft) ${ }^{5}$, and automobile cost per mile is a user input. Scheduled airline trip times and frequencies are from the $\mathrm{OAG}^{6}$ and air fares are from the FAA $10 \%$ ticket sample (DB1B) ${ }^{7}$ data with a generic fare based on distance when DB1B data are insufficient for the less traveled routes. Airport choice is modeled by examining fares and total trip times between up to 3 airports each at both the trip origin and destination. TSAM provides detailed analysis of the results of the mode choice module. Data of particular interest for this report were total county-to-county trips by mode, the airport-to-airport enplanements for the trip origin and trip destination airports, travel time summaries, and average trip distance for each mode. Future demand and thus schedules, the benefits of NGATS goals on National and individual airport passenger demand along with value of passenger time saved, and Trust Fund receipts from passenger fees can readily be determined from this body of data.

\section{Methodology}

A detailed description of TSAM, TSAM methodology, and supporting data bases is given in references 1 and 2. The architecture of the Transportation System Analysis Model (TSAM), developed by Virginia Tech and NASA Langley consists of several main modules; Trip Generation, Trip Distribution and Mode Choice. Several other modules exist that further analyze the output from the mode choice or prepare inputs to other programs, such as National Airspace System (NAS) simulation, ACES ${ }^{8}$. TSAM improves on traditional transportation analysis models by first modeling all long distance travel (one way distance greater that 100 miles) and then projecting the mode choices of travelers based on trip characteristics and traveler demographics. Long distance travel rates are generated at the county level from the 1995 American Travel Survey ${ }^{3}$ as a function of whether the trip is for business or personal travel and as a function of household income for 5 income levels for each of 3091 counties in the U.S. Although the trip rates are static with income level, the US per capita trip rate increases over time due to a shift in the demographics toward higher income levels. Detailed demographics are projected to 2030 via the Woods and Poole Complete Economic and Demographic Data Source ${ }^{4}$.

Once long distance trip origins have been projected, trip destinations are determined through a Trip Distribution Module that applies a gravity model with attractiveness factors applied to travel destinations. Unless demographics or trip rates are modified to model alternate future scenarios, the Trip Generation and Trip Distribution Module outputs for each year are stored. The analysis of the choice of travel modes for future travelers for these trips starts with the Mode Choice Module.

Existing transportation modes, such as automobile and commercial air, which are the predominate modes of business and personal long distance transportation are modeled. The performance and cost can be modified to model the introduction of new vehicles. For example, the introduction of faster and more fuel efficient aircraft could lead to lower airline costs and higher utilization, and thus gain more airline passengers by diversion from travel by automobile. New modes (or vehicle capabilities) can also be modeled and the demand for the new mode determined by cost and/or time advantages provided to long distance travelers.

A traveler's mode choice is a function of cash trip costs and value of time for business travel or personal travel for each of the 5 income levels. Existing modes such as automobile and scheduled air are well defined, and the model output has been calibrated with the American Travel Survey data. Trip times are determined as total one way trip times 
from the centroid of population in the county of origin to the centroid of population in the county of destination. Automobile trip times and distance are determined from MapPoint ${ }^{5}$ routing which yields automobile mileage and time for the trip. Schedule airline times and costs come from $\mathrm{OAG}^{6}$ and FAA $10 \%$ ticket sample data (DB1B) ${ }^{7}$. Drive time to and from airports is computed from MapPoint. Time taken to check-in time or origin airport transit time is a user input variable and is a function of airport size, thus giving the capability to project benefits from an improved (faster) security system. Airport departure transit time is also a function of airport size and is a user controlled variable.

The projected growth in air trips from and to each of the airports (enplanements) divided by the base year trips (enplanements) represent the growth factor in demand for each airport. A Fratar algorithm is applied to 19 February 2004 ETMS (Enhanced Traffic Management System) ${ }^{9}$ data to grow the scheduled commercial passenger traffic to meet future demands ${ }^{10}$. ETMS data for February 19, 2004 was chosen as a baseline day by the Evaluation and Analysis Directorate (EAD) of the $\mathrm{JPDO}^{11}$ because it was a heavy volume day with good weather. Other traffic in the ETMS data set, such as cargo, unscheduled air taxi and GA was grown at the average overall growth rate (military traffic was removed from the original data set). The method in reference 10 was modified to introduce new direct flights when warranted by demand and to replace smaller aircraft with larger aircraft between an airport pair when warranted by demand and flight frequency. The airport-to-airport enplanements matrix was examined for airport pairs with 25,000 or more annual enplanements between the airports and no direct service between the airports. Two direct flights per day of a 50 passenger regional jet were introduced when the threshold of 25,000 annual enplanements was exceeded and the passengers and flights removed from being routed though the shortest connecting hub route. Larger aircraft were also introduced on routes with sufficiently high flight frequency, such that the economics of a larger aircraft are more important to the market than increasing schedule frequency. An algorithm derived from curves in the Airbus Global Market Forecast ${ }^{12}$ was used to substitute larger aircraft into service on appropriate routes. (Note: This is a refinement beyond the use of the average number seats per aircraft adjustment most often used by forecasters rather than a detailed examination of the demand growth and frequency of the resulting traffic at the airport pair level.)

\section{Future Scheduled Air Travel Projections}

A number of projections of passenger demand for scheduled air service and the resulting airline schedules designed to meet passenger travel time preferences were performed. Projections of interest to the JPDO/EAD were for the year 2014 and for 2 and 3 times the 2004 demand (2X and 3X 2004 enplanements).

Future air travel was projected by exercising TSAM with automobile and scheduled air as two competing modes. Growth in scheduled air service demand is driven by both demographics and the continuing reduction in the cost of air travel in real or constant year dollars. Note that demographic and airline cost numbers are in constant year 2000 dollars in TSAM. Fare yield reductions differ for major and regional carriers and the reduction factors used in TSAM are an average reduction weighted by the projected ASM's (Available Seat Miles) flown by the major carriers and by the regional carriers.

Figure 1 presents data for three fare yield scenarios. The FAA Aerospace Forecasts Fiscal Years 2005-2016 ${ }^{13}$ projects fare yields that continue to decrease in real dollar terms from the lows that were set in 2004-2005. In year 2000 dollars, 2014 fares would be reduced 38\% and extrapolating the trend to 2025 fares would be reduced $46 \%$. The numbers are reflected in the highest growth curves of the sets of curves for non-business and business travel in figure 1 . However the trend in fare yield that has occurred since the FAA forecast was published isn't supporting the trend as projected. The authors believe that a more reasonable long term projection is the "return-to-the-mean" concept. This concept is based on a strong tendency for over/under validations to return to the long term trends based on the economic forces of air travel that have a longer history. The attacks of $9 / 11$ resulted in over capacity and reduced fares that the industry is currently (or will be) correcting, and in time would be expected to return to fares and capacity based on competitive forces that existed between deregulation and early 2001. Fare yield reductions of $22 \%$ and $35 \%$ for 2014 and 2025, respectively, are projected and the resulting enplanements are the middle curves in the two sets of curves. This fare yield scenario results in a total (business plus personal or non business travel) increase in enplanements of $47 \%$ and $89 \%$ in 2014 and 2025, respectively, with respect to 2000 levels (or 2004 since 2004 enplanements were roughly equal to 2000). The bottom curve in the two sets is a constant (no decrease in inflation adjusted dollars) fare yield curve illustrating the demand resulting from population and 
income growth. Note that non-business travel is very sensitive to ticket price whereas business travel is fairly inelastic with ticket price, and as will be shown later, business travel is more sensitive to time savings.

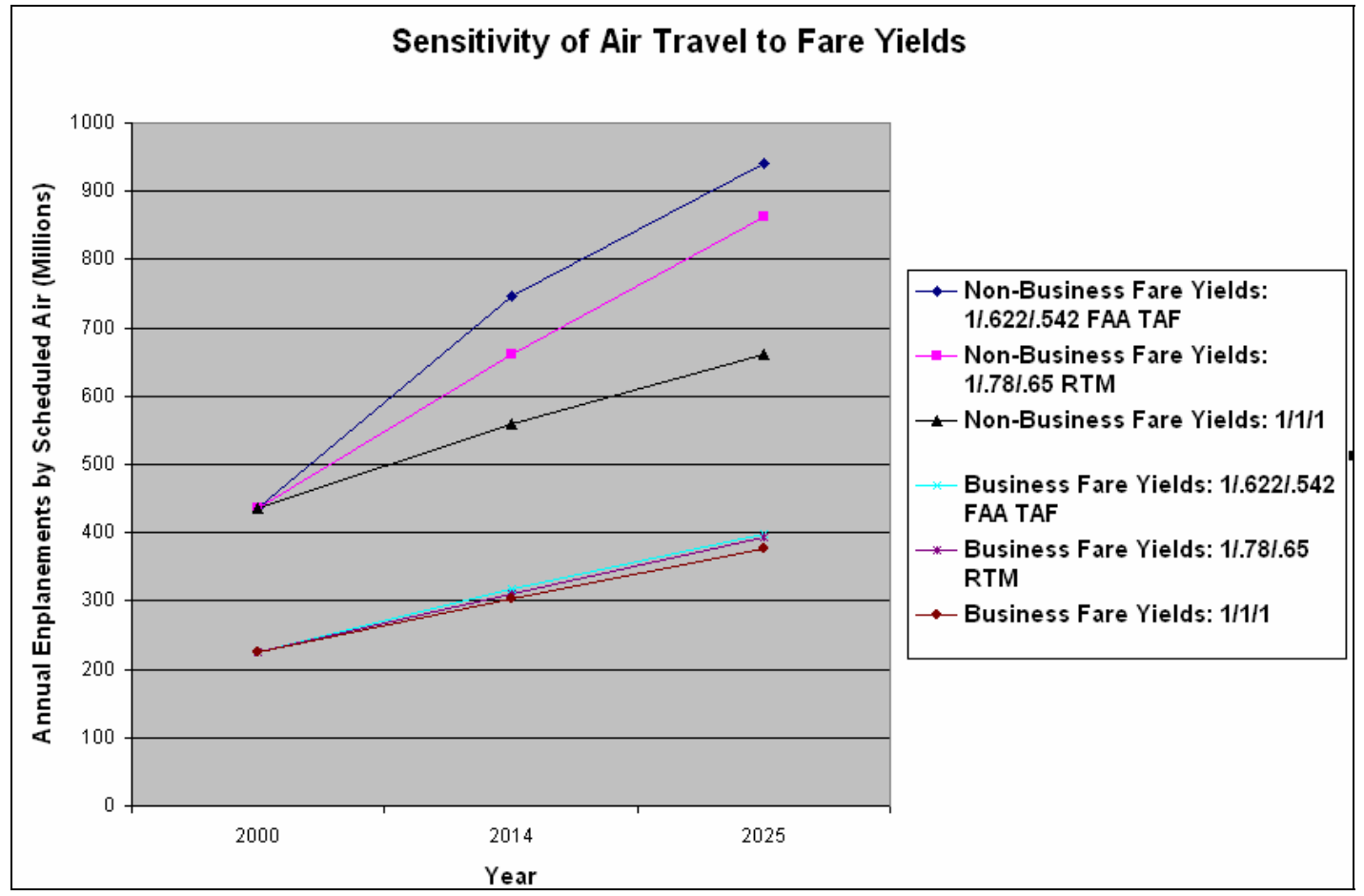

\section{Figure 1-Sensitivity of Air Travel to Fare Yields}

Some noteworthy observations of extrapolating the curves are that the time to reach twice the 2004 enplanements would be approximately 2049 if fare yields were to remain at 2000 levels. However, the time to reach 2X enplanements is only 2023, if fare yields are reduced at the rate projected by the FAA Aerospace Forecast Fiscal Years 2005-2016. Fare yield projections not only strongly influence growth rates, but effect to a lesser extent the origins and destination of air travelers. Lower ticket prices more rapidly increase non-business travel that favors tourist destinations or areas with the most rapidly growing populations, which are often attractive retirement areas for affluent retirees, and are often served by smaller airports. Some of these areas have growth factors well in excess of the $2 \mathrm{X}$ overall.

If fare yields follow the "return to the mean "reductions, a 3X level of total enplanements is projected to occur in mid 2047 and determining individual airport enplanements required extrapolating TSAM results. This date is well beyond the 2030 demographic projections with the TSAM data base. The $3 \mathrm{X}$ total enplanements case was developed by extrapolating the growth rates for the individual airports from 2020 to 2025 for another 22.7 years into the future. The rates of reduction in fare yield and the county demographic changes projected to occur from 2020 to 2025 are thus projected to continue and have a strong effect on how demand develops in the long term projection.

Scheduled passenger traffic operations were also projected for the 2014, 2X, and 3X case. Tables 1 to 3 present summaries of number flights of the projected demand resulting when the Fratar algorithm and scheduling methodology is applied. The numbers of flights are shown for the overall NAS and for two large hub airports, Atlanta Hartsfield and Chicago O’Hare. 


\begin{tabular}{|c|c|c|c|c|c|c|}
\hline \multicolumn{7}{|c|}{$\begin{array}{l}\text { Commercial Operations based on } 19 \text { Feb } 2004 \\
2014 \text { Passenger Demand with 25\% Fare Yield Reduction }\end{array}$} \\
\hline & TOTAL & GROWTH & ATL & GROWTH & ORD & GROWTH \\
\hline 2004 & 42796 & & 2620 & & 2773 & \\
\hline 2014 & 65275 & $53 \%$ & 4482 & $71 \%$ & 4298 & $55 \%$ \\
\hline $\begin{array}{l}\text { Direct } \\
\text { Flights }\end{array}$ & 62998 & $47 \%$ & 3943 & $50 \%$ & 4016 & $45 \%$ \\
\hline $\begin{array}{l}\text { Direct } \\
\text { Flights+ } \\
\text { Larger } \\
\text { Aircraft }\end{array}$ & 62009 & $45 \%$ & 3747 & $43 \%$ & 3880 & $40 \%$ \\
\hline
\end{tabular}

Table 1. Commercial Operations 2014 Demand

Table 1 presents the 2014 projections. Note that the enplanements for 2014 in Table 1 are for a slightly larger fare yield reduction, $25 \%$ rather that 22\%, than for 2014 in figure 1 .This results in about $2.5 \%$ more enplanements over those in figure 1, but with the unknowns in future fare yields, the results in the table are typical of mid level 2014 projections. The doubling and tripling of 2004 overall domestic enplanements shown in Tables 2 and 3 were solved for exactly by either interpolating or extrapolating the TSAM yearly growth rates of each airport's enplanements. The 3X case occurs well beyond the TSAM demographic data base and requires extrapolating the 2020/2025 growth rate for each airport for approximately an additional 20 years. The FAA fare yield projection trends were used in calculating the $2 \mathrm{X}$ and $3 \mathrm{X}$ enplanement demands. The fare yield assumptions are still important factors in the $2 \mathrm{X}$ and $3 \mathrm{X}$ cases because they will result in not only determining the year in which the demand develops, but also in changes in the balance between non-business or leisure travel and business travel. The balance between nonbusiness and business travel has an impact on which airports the travel originates and/or the destination airports. Several trends are apparent in the three tables. Before introducing direct fights and larger aircraft where appropriate, the percentage increase in flights slightly exceeds the percentage increase in demand. Demographic trends favor the segment of the market that tends to be served by smaller than average aircraft rather than the large metropolitan areas served by a greater portion of large aircraft. The compatibility between fare yield reductions and increasing service to smaller markets was not currently addressed, but is not beyond the scope of TSAM. The effects of direct flights and larger aircraft on reducing the number of operations or flights, as would be expected, are indicated to be more significant at the hub airports than to the overall system. Also as would be expected, as demand increases the opportunity to introduce direct flights and larger aircraft is enhanced and the resulting benefits increases significantly. The detail passenger trip data from TSAM enables these projections to be carried out at the airport pair level which should result in a better match with a valid business case than conventional approaches to air traffic projections. 


\begin{tabular}{|c|c|c|c|c|c|c|}
\hline \multicolumn{7}{|c|}{$\begin{array}{l}\text { Commercial Operations based on } 19 \text { Feb } 2004 \\
\text { 2x Passenger Demand }\end{array}$} \\
\hline & TOTAL & GROWTH & ATL & GROWTH & ORD & GROWTH \\
\hline 2004 & 42796 & & 2620 & & 2773 & \\
\hline $\mathrm{X} 2$ & \begin{tabular}{|l|l|l|}
87428 \\
\end{tabular} & $104 \%$ & 6465 & $147 \%$ & 5936 & $114 \%$ \\
\hline $\begin{array}{l}\text { Direct } \\
\text { Flights }\end{array}$ & 83362 & $95 \%$ & 5512 & $110 \%$ & 5505 & $99 \%$ \\
\hline $\begin{array}{l}\text { Direct } \\
\text { Flights+ } \\
\text { Larger } \\
\text { Aircraft }\end{array}$ & 78654 & $84 \%$ & 4704 & $\mathbf{8 0 \%}$ & 4808 & $73 \%$ \\
\hline
\end{tabular}

Table 2. Commercial Operations at 2X Passenger Demand

\begin{tabular}{|c|c|c|c|c|c|c|}
\hline & \multicolumn{6}{|c|}{$\begin{array}{c}\text { Commercial Operations based on } 19 \text { Feb } 2004 \\
\text { 3x Passenger Demand }\end{array}$} \\
\hline & TOTAL & GROWTH & ATL & GROWTH & ORD & GROWTH \\
\hline 2004 & 42796 & & 2620 & & 2773 & \\
\hline X3 & 130960 & $206 \%$ & 10162 & $288 \%$ & 8577 & $209 \%$ \\
\hline $\begin{array}{l}\text { Direct } \\
\text { Flights }\end{array}$ & 122816 & $187 \%$ & 8318 & $217 \%$ & 7773 & $180 \%$ \\
\hline $\begin{array}{l}\text { Direct } \\
\text { Flights+ } \\
\text { Larger } \\
\text { Aircraft }\end{array}$ & 104161 & $143 \%$ & 5596 & $114 \%$ & 5687 & $105 \%$ \\
\hline
\end{tabular}

\section{Table 3. Commercial Operations at 3X Passenger Demand}

TSAM data when coupled with the modified Future Air Traffic Growth and Schedule Model ${ }^{10}$ further provides the data necessary to examine the impact of demand at individual airports. Arrivals and departures in 15 minute epochs at Atlanta Hartsfield are shown in figure 2 for the 2004 baseline day, the $2 \mathrm{X}$ operations before introducing larger aircraft and direct flights, and $2 \mathrm{X}$ afterwards. This data can be used to not only project flight delays, but to examine demand/capacity matching. Delays or demand/capacity matching measures can be fed back through TSAM to determine the system level response. 


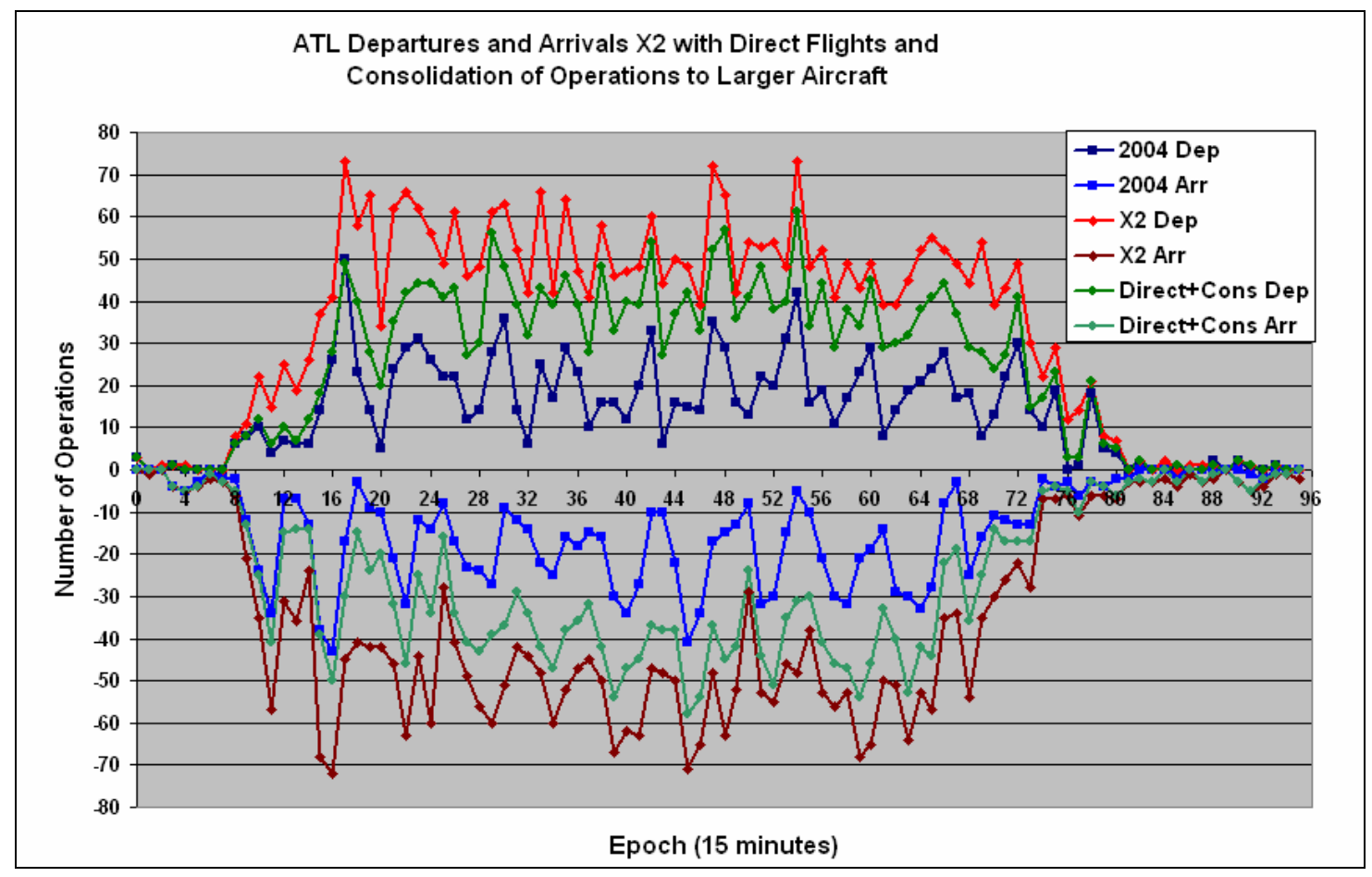

Figure 2. Atlanta (ATL) Departures and Arrivals for 2X Passenger Demand

\section{Effect of NGATS on Passenger Demand and Passenger Benefits}

Benefits assessments associated with improvements in the future NAS are usually compared against the potential increased flight delays expected to occur in absence of the improvements and the cost of those delays and cancelled flights to the airlines. Those costs are assumed to be passed on to the consumer resulting in less or constrained demand. The benefits in terms of system capacity improvements, such as NGATS, are defined as the difference between the improved ability to meet demand and the constrained demand. This is a valid and reasonable estimate of the benefits, but probably also underestimates the airlines ability to respond to meeting demand in a system with selected constraints.

Another side of the benefits is those accruing to travelers and the fact that NGATS itself should be expected to increase demand over the unconstrained demand without NGATS. One of NGATS stated objectives ${ }^{14}$ is to reduce transit time and increase predictability (domestic curb-to-curb time cut by 30\%). This objective was approximated in TSAM by reducing airport transit time and scheduled flight (block) time by 5\%. TSAM times for airport transit times are a function of airport size with large hub airports having times twice those of non-hub airports. The baseline and NGATS airport transit times are shown in Table 4 . The 5\% reduction in scheduled flight time only partially removes the delays built into today's schedules, but would require NGATS to consistently move air traffic through the system more efficiently while serving a much increased volume of traffic. The $5 \%$ reduction is based upon the gate-to-gate time, so improved airport surface operations will also contribute to the time saved with NGATS. 
- NGATS Expand Capacity - Objective 2. Reduce transit time and increase predictability ( domestic curb-to-curb time cut by $\mathbf{3 0 \% \text { ) }}$

- This objective was approximated by reducing airport transit time and scheduled flight time by $5 \%$

- Airport transit times: Origin Airport

Destination Airport

Large hubs

Medium hubs

Small hubs

Non-hubs
2.0 hrs to $1.0 \mathrm{hr}$

1.5 hrs to $1.0 \mathrm{hr}$

1.25 hrs to $45 \mathrm{~min}$

1.0 hrs to $45 \mathrm{~min}$
$45 \mathrm{~min}$ to $30 \mathrm{~min}$

$45 \mathrm{~min}$ to $30 \mathrm{~min}$

$30 \mathrm{~min}$ to $20 \mathrm{~min}$

$30 \mathrm{~min}$ to $20 \mathrm{~min}$

- A 5\% reduction in scheduled flight time only partially removes the delay (padding) already built in today's schedules

Table 3. NGATS Objectives

Figure 3 presents a build-up of the elements that promote increased passenger demand in 2025 with respect to 2000 enplanements. Without the NGATS Expand Capacity- Objective 2, the number of enplanements in 2025 using the return-to-the-mean fare yield projection would almost double ( $92 \%$ increase) with a little more than $60 \%$ of the increase coming from population and real income levels increases over the time period. The other, less than $40 \%$, comes from the projected 35\% reduction in real fare yields. The achievement of the dramatic time saving of NGATS Objective 2 could stimulate the passenger demand (right hand bar) almost as much as the expected reduction in real fare yields. TSAM calculates that an additional 163M enplanements per year would result from the curb-to-curb time savings. Figures 4 and 5 provide insight into this increased demand. Figure 4 shows there is a much larger percentage stimulation of business travel than non-business. Business enplanements increase $16 \%$ and non-business enplanements increase $12 \%$. Business travel is very time sensitive, so the NGATS time savings are valued much more by business travelers. NGATS thus has important revenue implication for the airlines beyond the cost of aircraft delays since the business traveler generally pays significantly higher fares. 


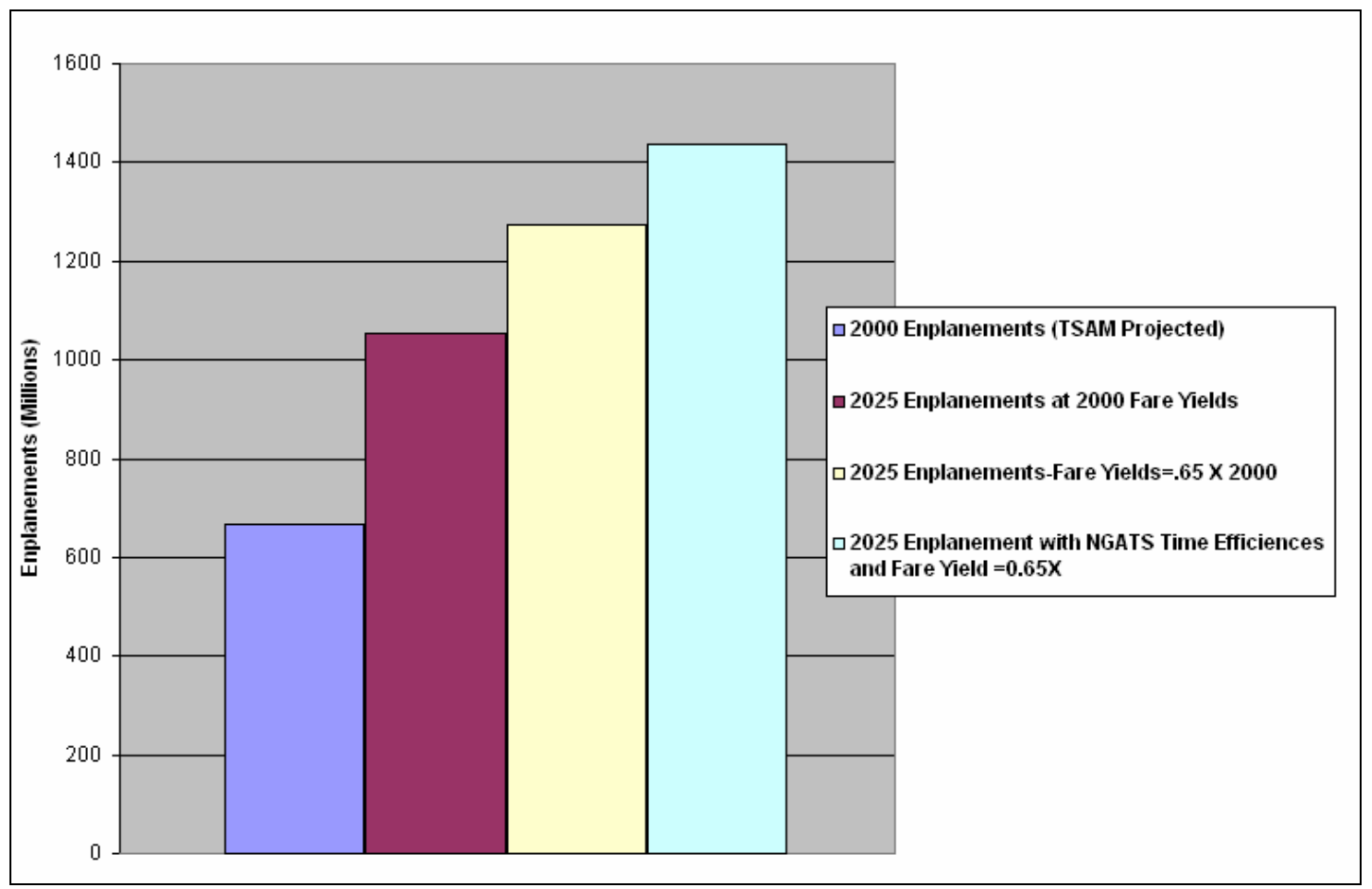

Figure 3. Breakdown in Enplanement Growth by Effect

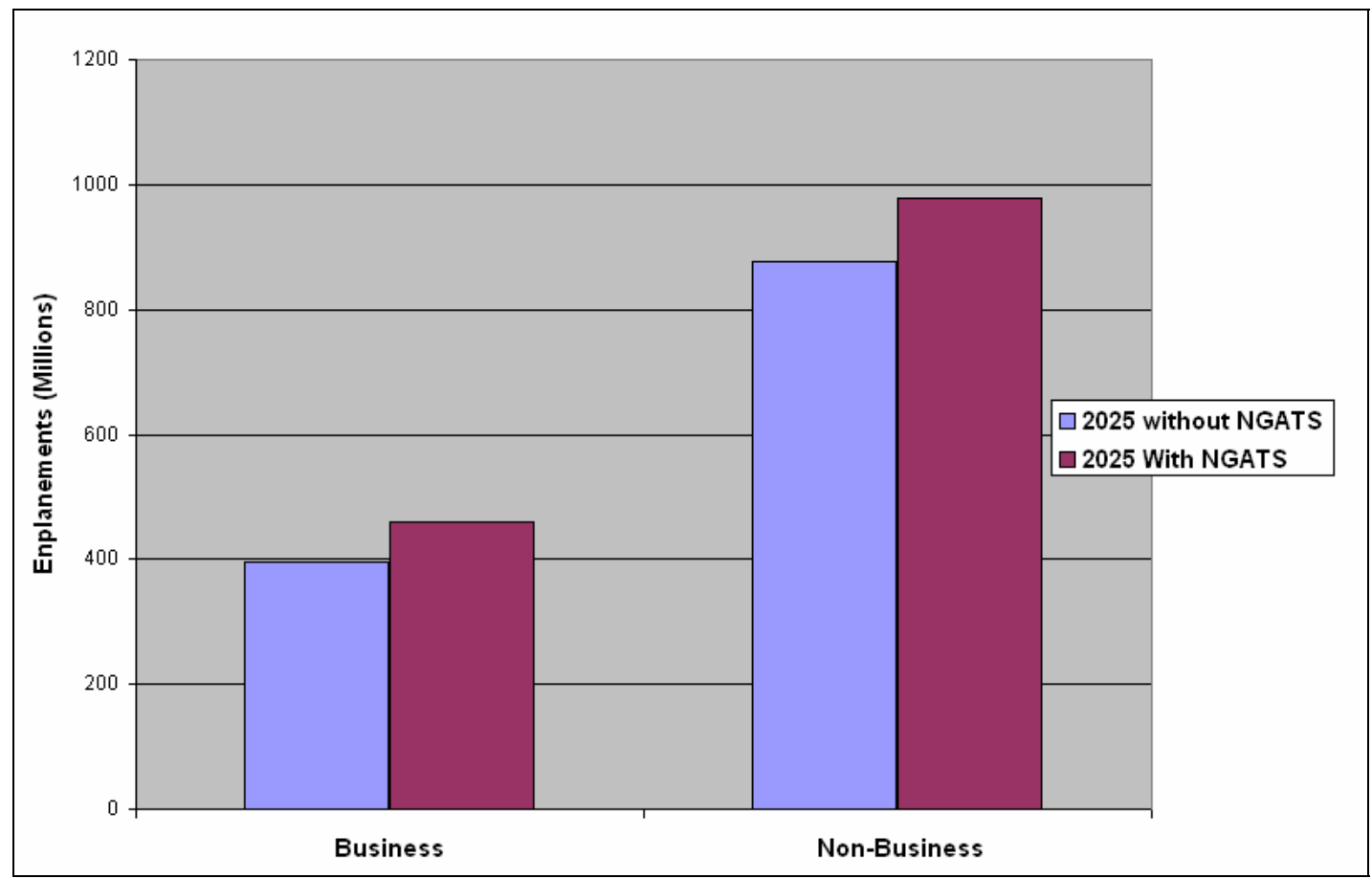

Figure 4. Effects of NGATS on Demand in 2025 
Figure 5 shows that virtually all of the NGATS stimulated trips are at distances less than 700 statute miles with the most dramatic increase in the 250 to 400 mile range. Trip distances are one way great circle distances, so the driving distance on some of the shorter trips may be considerably longer because of natural barriers. In short, NGATS would re-capture much of that portion of the market which was lost due to $9 / 11$ and the resulting time consuming nightmare of transiting airports. The attacks of 9/11 resulted in many shorter range trips being switched to automobiles since air travel provide little or no time advantage. Note that TSAM can also identify the nature of demand decreases due to increasing airport transit times, such as the need to check all luggage and spend extra time at the egress airport waiting to reclaim luggage.

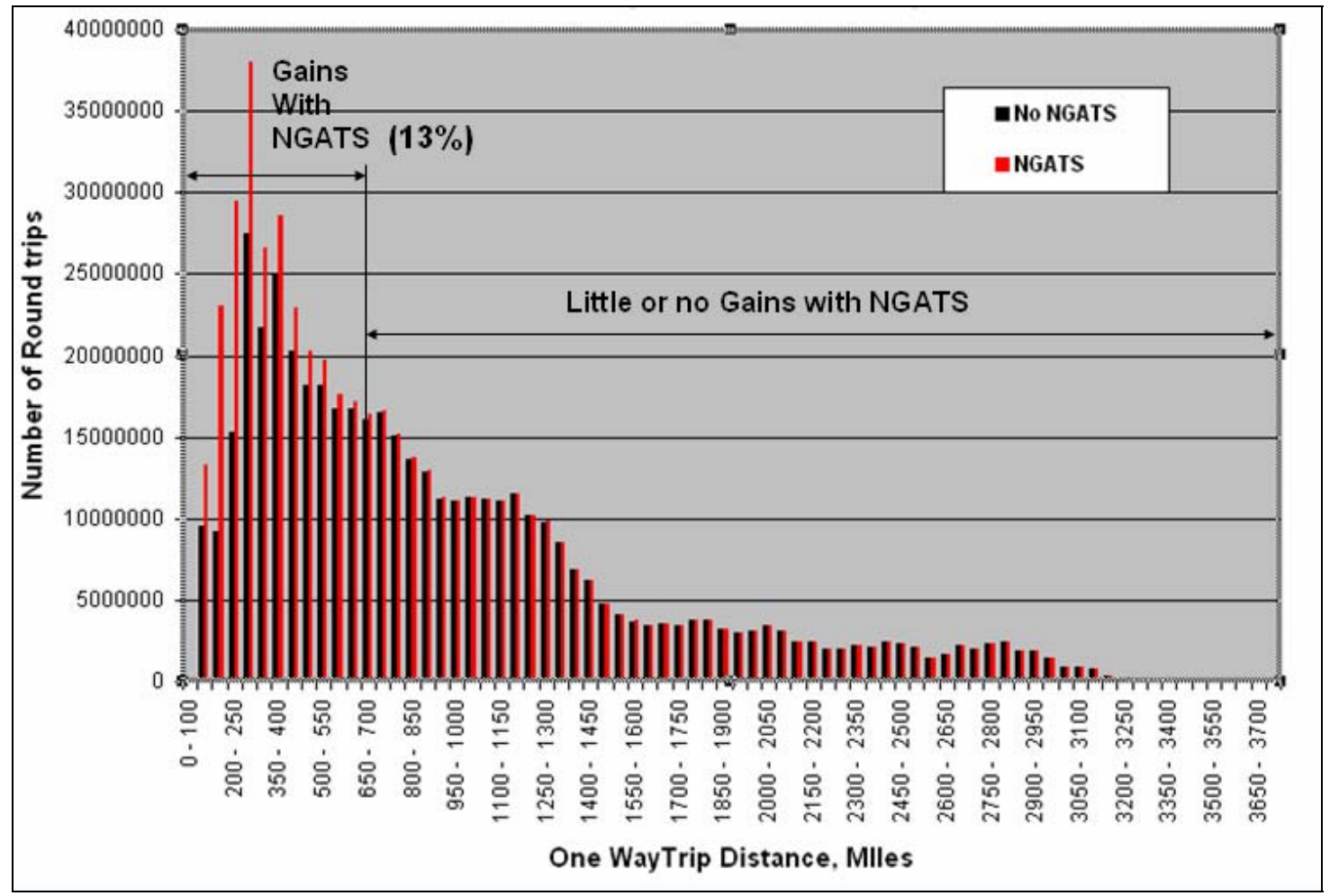

Figure 5. Annual Scheduled Air Round Trips vs Distance

Table 5 presents the numbers and logic for determining the value of NGATS benefits to domestic travelers. NGATS results in time saved from two sources, (1) all travelers already traveling by scheduled air save significant amounts of time and (2) in addition, time is saved by travelers who switch from automobile to air due to its revised time advantage. Total time saved by NGATS implementation is almost a billion hours in a single year for 2025. Using FAA values of time for passengers from the FAA economic values and investment guide ${ }^{15}$ and adjusting the values to 2006, total value of time saved is $\$ 32.2 \mathrm{~B}$ in 2006 dollars. The benefits are in addition to the reduced cost of delays and canceled flights to the airlines that result from a severely constrained system. That benefit has been estimated by the JPDO/EAD to be approximately \$40B per year in today’s dollars in 2025. 


\section{NGATS Value to Domestic Travel}

- Business travelers save 308.2 million hours

- Which includes -

- Time saved on flights passengers were already on

- Time saved when travelers switched modes from automobile to commercial air

- FAA guide for Economic Values for FAA Investment and Regulatory Decisions places $\$ 40.10 /$ hour (Year $2000 \$$ ) on business travel value of time. Adjusted to Year $2006 \$$ the value becomes $\$ 47.39$

- 308.2M hours $\mathrm{X} \$ 47.39 /$ hour $=\$ 14.6 \mathrm{~B}$

- Personal travelers save 676.6 million hours

- Which includes -

- Time saved on flights passengers were already on

- Time saved when travelers switched modes from automobile to commercial air

- FAA guide for personal travel value of time is $\$ 23.30$ /hour (Year $2000 \$$ ). Adjusted to Year $2006 \$$ the value becomes $\$ 27.53$

- $676.6 \mathrm{M}$ hours $\mathrm{X} \$ 27.53 / \mathrm{hour}=\$ 18.6 \mathrm{~B}$

- Total value of traveler time saved $=\$ 33.2 \mathrm{~B}$

Table 4. Value of NGATS to Air Travelers

\section{Airport and Airway Trust Fund Receipts from the Transportation of Persons}

In 2000 the Airport and Airway Trust Fund receipts from the domestic transportation of persons was a little over 7 billion dollars which was $66 \%$ of the total trust fund receipts. By 2003 passenger receipts had dropped below 5 billion dollars in current dollars and even more in constant or year 2000 dollar value. Since TSAM generates detailed trip data, as to the numbers of trips and lengths of trips, this data when combined with fare yield, projected future fare yields, and the tax structure can easily be used to project future tax and fee receipts. The FAA breakout of fees for the domestic transportation of persons includes the domestic ticket tax, domestic flight segment tax, rural airports tax, and frequent flyer tax. TSAM numbers can account for these tax sources with the exception of the frequent flyer tax. This tax is imposed on the payment for frequent flyer miles purchased by credit card or other companies and the amounts that airlines receive in joint venture credit card arrangements, so it is not directly related to passenger demand as projected by TSAM. However, the frequent flyer tax is a very small percentage of the overall tax revenues. The $7.5 \%$ domestic ticket tax and the inflation indexed domestic flight segment fee make-up approximately $96 \%$ of the passenger receipts.

Figure 6 shows that the year 2000 passenger transportation receipts of 7 billion dollars are accurately predicted by TSAM at only slightly over 7 billion dollars. The 2025 trust fund receipts are projected to rise approximately $50 \%$ in real dollar terms. The two middle bars are for the return-to-the-mean fare yield reduction to $65 \%$ of year 2000 yields for the NAS with and without NGATS. The NGATS scenario results in approximately 0.9 billion dollars (2000\$) increase in passenger receipts. However, if the FAA fare yield projection to 54\% of 2000 levels occurs, the NGATS benefit is offset by the reduction in ticket tax receipts due to lower fares. Figure 7 presents another view of the future of passenger receipts if today's rates are maintained. Although passenger receipts are up roughly 50\%, the number of passengers, depending on the fare yield scenario, are up somewhere between $92 \%$ and $139 \%$ (figure 3). Receipts per passenger, shown in figure 7, drop as fare yields are reduced. NGATS curb-to-curb time saving would result in additional shorter distance lower fare air trips. Although NGATS results in a surge in enplanements, the 
shorter flight segments yield less ticket tax per flight. If the cost of serving each passenger remains constant, a 33\% to $40 \%$ shortfall in passenger receipts with respect to 2000 in year 2000 dollars will develop with the current tax and fee structure. The segment tax, which is inflation indexed, will be a larger share of the passenger receipts under the 2025 projections. Overall passenger fares are projected to continue to fall in real dollars, thus reducing receipts from the ticket tax. NGATS curb-to-curb time savings would increase growth in shorter flight segments on which the segment fee accounts for a greater portion of tax receipts. The Airport and Airway Trust Fund is due for reauthorization in September 2007 and the fee structure is likely to change. As show here, TSAM can be used to asses the effects of fee changes and to provide insight in future policy scenarios as well as their effect on passenger demand. For instance, any change in demand due to a new excise tax structure could be quickly projected.

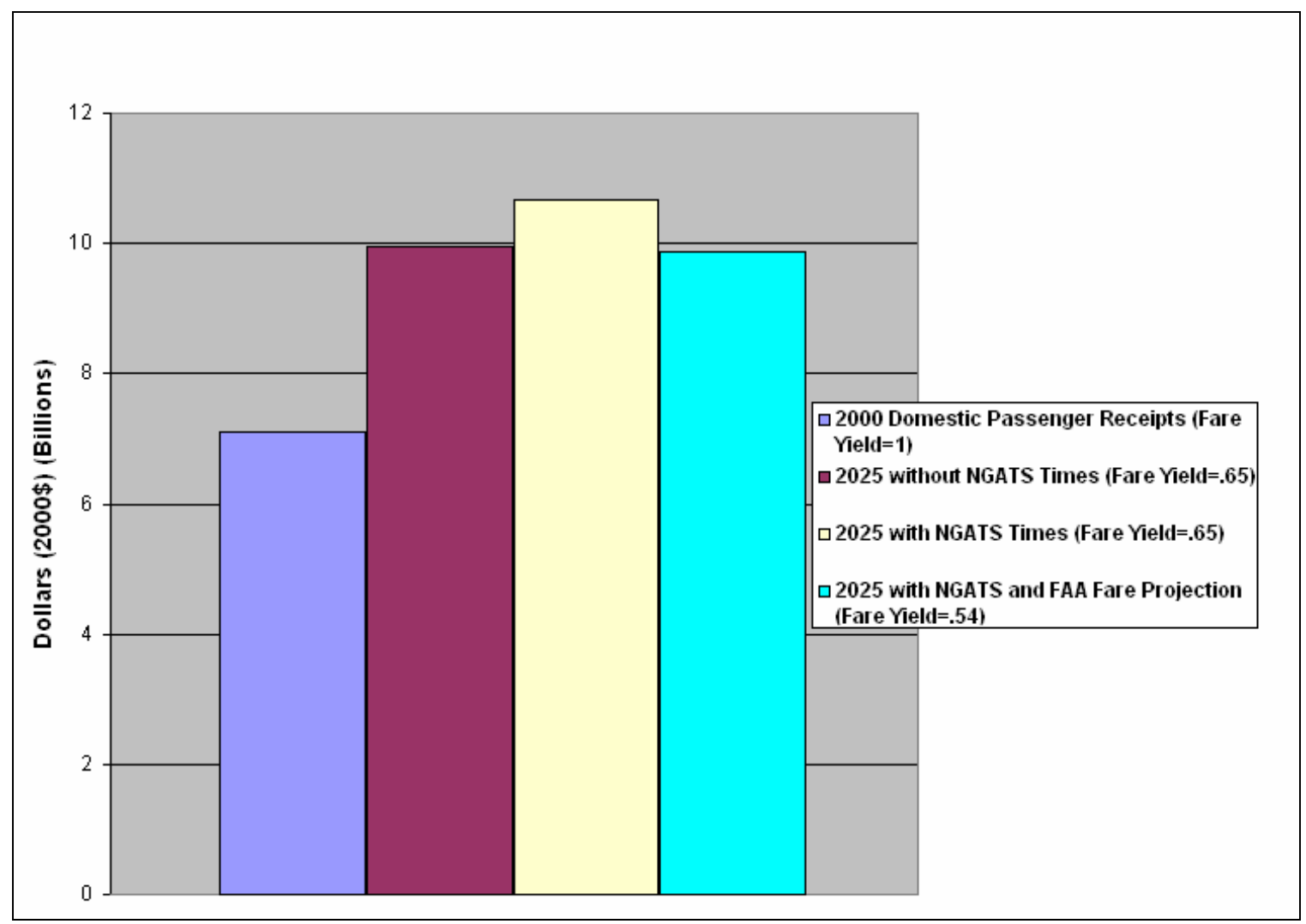

Figure 6. Airport and Airway Trust Fund Receipts (2000\$) 


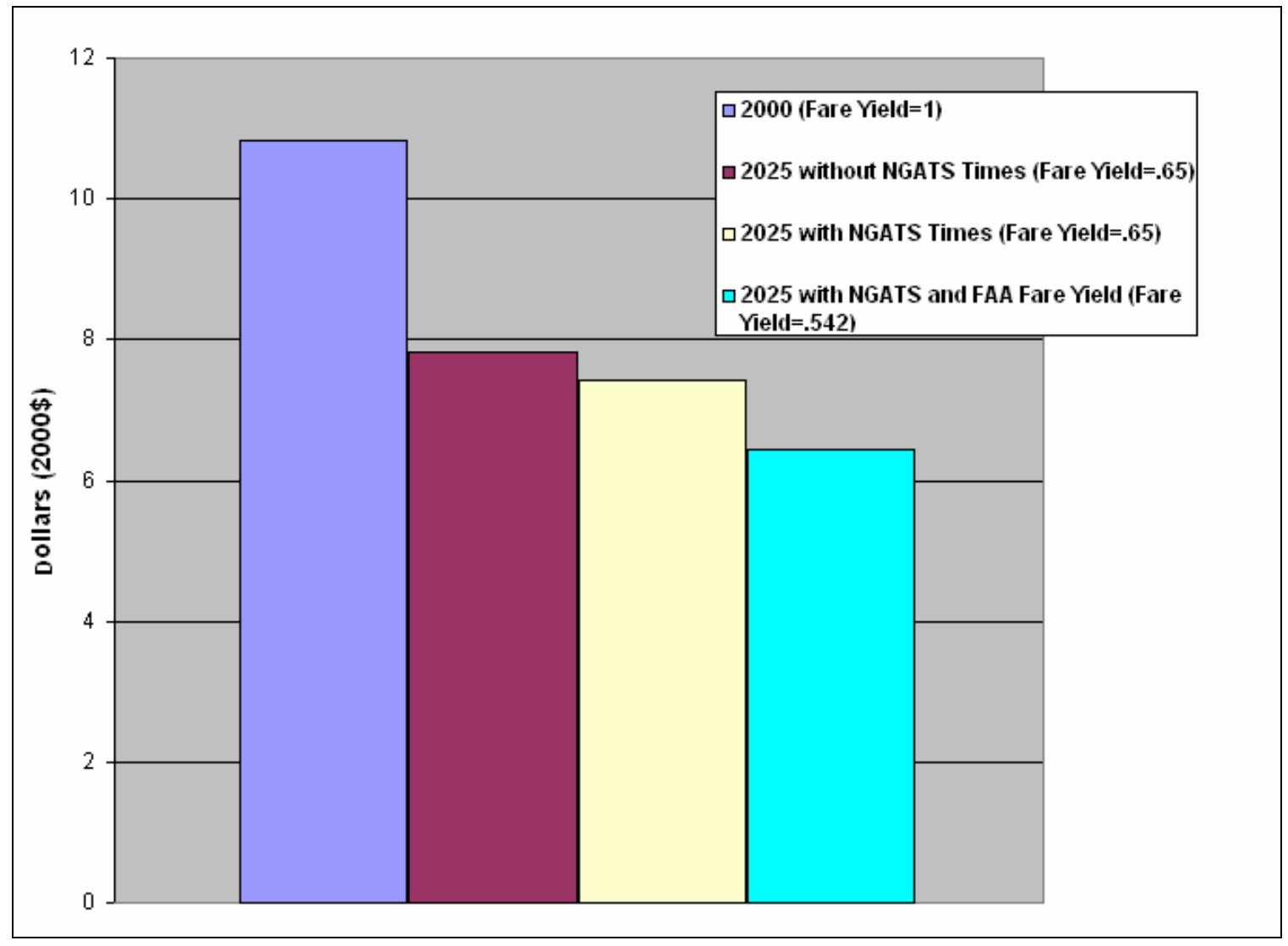

Figure 7. Trust Fund Receipts Per Domestic Enplanement

\section{Concluding Remarks}

The Transportation Systems Analysis Model (TSAM) developed by Virginia Tech's Air Transportation Systems Lab and NASA Langley has proven to be a versatile tool in analyzing demand and changes in demand when new vehicles and/or technology is inserted into the long distance (100 or more miles one-way) transportation system. Projections are also easily performed to analyze changes in demand as a result of fare yield increases or decreases, airport transit times, scheduled flight times, ticket taxes, reductions or increases in flight delays, and so on. In short, TSAM can provide detailed analysis of the effects of a full range of NASA and FAA aviation projects and other system changes on the demand for air travel. TSAM produces detailed passenger demand at the county and airport level. The level of detail provides data from which potential future airline schedules can be formulated that meet the projected demand. TSAM has been used to project the passenger demand for very light jet (VLJ) air taxi service, scheduled airline demand growth and future schedules, Next Generation Air Transportation System (NGATS) benefits, and future passenger revenues for the Airport and Airway Trust Fund. This paper has presented the application of TSAM to modeling future scheduled air passenger demand and resulting airline schedules, the impact and benefits of NGATS goals and objectives on passenger demand, along with projections for passenger fee receipts for several scenarios for the FAA Airport and Airway Trust Fund . 


\section{References}

${ }^{1}$ A.A. Trani, Baik, H. ,Swingle H.S., and S. Ashiabor, Integrated Model to Study the Small Aircraft Transportation System, Transportation Research Record Vol. 1850, National Academy Press, Washington, DC, pp. 1-10, 2004

${ }^{2}$ Viken, J., Dollyhigh, S., Smith, J., Trani, A., Baik, H., Hinze, N., Ashiabor, S., Utilizing Traveler Demand Modeling to Predict Future Commercial Flight Schedules in the NAS, AIAA Meeting Papers on Disc, Vol 11, No.17, AIAA, Reston, VA, 2006

${ }^{3}$ ATS, American Travel Survey, Bureau of Transportation Statistics, http://www.bts.gov/publications/1995_american_travel_survey/index.html, 1995.

${ }^{3}$ Woods \& Poole Economics, http://www.woodsandpoole.com/, 2005.

${ }^{5}$ Microsoft MapPoint, http://www.microsoft.com/mappoint/products/2004/, 2004

${ }^{6}$ OAG, Official Airline Guide, http://www.oag.com/, 2004.

${ }^{7}$ DB1B, Bureau of Transportation Statistics (BTS),

http://www.transtats.bts.gov/DatabaseInfo.asp?DB_ID=125\&DB_URL

${ }^{8}$ CTOD 7.39 - Airspace Concept Evaluation System (ACES) Build 3 Software User Manual, 30 September 2004, Contract Number NAS2-00015, Prepared by, Raytheon ATMSDI Team

${ }^{9}$ Anon, Enhanced Traffic Management System (ETMS), Reference Manual, Version 7.6, Volpe National

Transportation Systems Center, Report No. VNTSC-DTS56-TMS-004, May 2003,

http://www2.faa.gov/tfmModernization/

${ }^{10}$ Smith, J., Dollyhigh, S., Future Air Traffic Growth and Schedule Model NASA/CR-2004-213027, Jan. 2004

${ }^{11}$ Joint Planning and Development Office, http://www.jpdo.aero

${ }^{12}$ Airbus Global Market Forecast, 2005 to 2024

http://www.airbus.com/en/myairbus/global_market_forcast.html

${ }^{13}$ FAA Aerospace Forecasts Fiscal Years 2005-2016,

http://www.faa.gov/data_statistics/aviation/aerospace_forecasts/2005-2016/

${ }^{14}$ Next Generation Air Transportation System Integrated Plan, http://jpdo.aero/integrated_plan.html

${ }^{15}$ Economic Values for Evaluation of FAA Investment and Regulatory Decisions, GRA Incorporated, DTFA 01-02C0020, May 2004,

http://www.faa.gov/regulations_policies/policy guidance/benefit_cost/media/050404 Critical Values Dec 31 Report

07Jan05.pdf 